\title{
Current state and perspectives of checkpoint inhibitors in ovarian cancer treatment
}

\author{
Thomas Bartl (D) • Valentina Paspalj · Stephan Polterauer · Christoph Grimm (D)
}

Received: 24 November 2019 / Accepted: 14 January 2020 / Published online: 17 February 2020

(C) The Author(s) 2020

Summary The introduction of checkpoint inhibitors (CPI) has set a paradigm shift within the therapies for a variety of advanced solid tumors. By altering key regulators of cellular immune response, so-called immune checkpoints, CPIs modulate peripheral cancer immune tolerance to induce cancer-targeted immune reactions. Response rates, however, vary significantly between different solid tumor types. A certain efficacy of CPIs has been described for gynecological malignancies, as the KEYNOTE-028 study reported an objective response rate (ORR) of $13.0 \%$ (95\% confidence interval [CI] 2.8-33.6) for endometrial and the CheckMate-358 study an ORR of $26.3 \%$ (95\% CI 9.1-51.2) for cervical cancer. With respect to epithelial ovarian cancer (EOC), recent evidence suggests only modest response, as the largest study to date by Matulonis et al. reported in 2019 that pembrolizumab induced an ORR of only $8.0 \%$ in 376 patients with EOC. Thus, latest clinical data indicate EOC to be rather "immunologically cold", most likely due to both an inherently low tumor mutational burden (TMB) and a subsequently limited cellular antigen presentation.

T. Bartl, MD · V. Paspalj, MD .

Assoc.-Prof. PD S. Polterauer, MD .

Assoc.-Prof. PD C. Grimm, MD ( $\triangle)$

Department of Obstetrics and Gynecology,

Division of General Gynecology and Gynecologic

Oncology, Medical University of Vienna, Waehringer

Guertel 18-20, 1090 Vienna, Austria

christoph.grimm@meduniwien.ac.at

T. Bartl, MD

thomas.bartl@meduniwien.ac.at

V. Paspalj, MD

valentina.paspalj@meduniwien.ac.at

Assoc.-Prof. PD S. Polterauer, MD

stephan.polterauer@meduniwien.ac.at
As CPI monotherapy therefore seems to be of limited clinical significance, ongoing clinical trials moved to combine CPI with PARP inhibitors and/or with antiangiogenic agents to elucidate possible synergistic antitumoral effects of these combinations. Despite promising preliminary data, the large phase 3 trials are still ongoing. To date, CPI monotherapy in OC remains highly experimental and is only to be administered within clinical studies and a highly selected group of patients.

Keywords Immune therapy - Ovarian cancer · Checkpoint inhibition

$\begin{array}{ll}\text { Abbreviations } & \\ \text { CPI } & \text { Checkpoint inhibitor } \\ \text { CPS } & \text { Combined positive score } \\ \text { CTLA-4 } & \text { Cytotoxic T lymphocyte antigen } 4 \\ \text { EOC } & \text { Epithelial ovarian cancer } \\ \text { iRAEs } & \text { Immune-related adverse events } \\ \text { ORR } & \text { Objective response rate } \\ \text { PD-1/PD-L1 } & \text { Programmed death receptor 1 } \\ \text { TMB } & \text { Tumor mutational burden }\end{array}$

Rationale of responsiveness to checkpoint inhibitor therapy

To date, monoclonal antibodies targeting either the PD-1/PD-L1 (programmed death receptor 1) or the CTLA-4 (cytotoxic T lymphocyte antigen 4) pathway have entered clinical trials for epithelial ovarian cancer (EOC). Both PD-1 and CTLA-4 are T-lymphocytespecific surface receptors which induce a negative feedback loop upon activation. Physiologically, these mechanisms prevent uncontrolled T-lymphocyte proliferation and mediate T-lymphocyte activation to be only transient. Whereas PD-1 binds a tissue-specific ligand (PD-L1) native to human cells, which is also 
expressed by solid tumors to evade host immune response, the exact mechanism of CTLA-4 action remains controversial. As part of immune-evasive strategies, however, tumor cells may pathologically downregulate PD-1/PD-L1 and/or CTLA-4 pathways, thereby impeding local immune response, which may allow tumor cells to thrive. Blocking either PD-1/PDL1 or CTLA- 4 by monoclonal antibodies may thereby potentiate the host immune response to cancer antigens, leading to clinical antitumor activity [1].

The responsiveness of EOC to checkpoint inhibitor (CPI) therapy, however, proved to be limited compared to other solid tumors. Recently, exploratory cancer genomics have suggested the tumor mutational burden (TMB) as an important biomarker of CPI therapy response: high TMB, which is usually found in tumors subjected to high carcinogen exposure, was associated with an increased inherent immunogenicity, as novel mutations may generate neoantigens that are not subjected to immune tolerance. As such, this may allow for an adaptive immune response [2]. Following this rationale, EOC may inherently not appear to be an ideal target for CPI monotherapy [3].

Trials combining CPIs with other targeted therapies have therefore moved to the center of clinical interest to create possible synergistic effects. PARP inhibitors seem to multiply TMB by amplifying DNA damage. Since DNA damage response is constitutively active in many solid tumors, PARP inhibition leads to an accumulation of cytoplasmatic DNA, which subsequently activates the STING pathway, attracting natural killer and T-lymphocytes. Thus, an immunogenic tumor microenvironment may be recreated, potentially improving CPI responsiveness in the case of combination with a PARP inhibitor [4].

Moreover, abnormal angiogenesis has been reported to compromise both the number of tumor infiltration lymphocytes and their functionality, most likely due to impaired extravasation of T-lymphocytes and by impeding the maturation of dendritic cells. Preclinical models have demonstrated upregulation of checkpoint molecules by VEGF inhibition. Therefore, a combination of CPI with antiangiogenic agents may more effectively block the PD-1/PD-L1 pathway than CPI monotherapy alone [5, 6].

\section{Activity of checkpoint inhibitor monotherapy for EOC}

Table 1 provides an overview of recent CPI studies targeting and blocking either the PD-1/PD-L1 pathway (pembrolizumab, durvalumab, atezolizumab, avelumab) or the CTLA-4 pathway (ipilimumab) in EOC. The results for CPI monotherapy revealed controversial results in EOC so far.

One of the most prominent and most studied CPIs is the PD1 inhibitor pembrolizumab. Its efficacy was evaluated in the KEYNOTE-100 study, which com- prised 376 patients with both recurrent platinumsensitive and platinum-resistant diseases receiving pembrolizumab (200 mg q3w). Primary endpoint was the objective response rate (ORR) stratified by PDL-1 expression levels. ORR differed according to the combined positive score (CPS) <1: ORR 5.0\% (95\% CI 2.0-10.0\%); CPS >1: ORR 10.2\% (95\% CI 6.3-15.2\%); CPS >10: $17.1 \%$ (95\% CI 9.7-27.0\%). Stratification of response according to CPS cut-offs may be of future interest both for patient selection and for prediction of therapy response, even though larger trials will be necessary to validate these results [9].

In contrast, two large-cohort randomized controlled phase 3 trials investigating the activity of avelumab were recently reported to be negative. Whereas the phase 1b JAVELIN Solid Tumor Trial reported response rates to avelumab $(10 \mathrm{mg} / \mathrm{kg} \mathrm{q} 2 \mathrm{w})$ comparable to other monotherapeutic CPI studies with an ORR of $9.6 \%$ (95\% CI 5.1-16.2) and a PFS of 2.6 months (95\% CI 1.4-2.8), two subsequent largecohort phase 3 combined studies were negative. The JAVELIN Ovarian 100 trial investigated the activity of avelumab in combination with carboplatin/ paclitaxel in the first-line treatment in 998 patients with advanced EOC. The trial was, however, terminated during an interim analysis for not meeting a significant increased PFS as primary outcome [13]. Final results of the JAVELIN Ovarian 200 trial assessing activity of avelumab ( $10 \mathrm{mg} / \mathrm{kg}$ q2w) compared to PLD $\left(40 \mathrm{mg} / \mathrm{m}^{2}\right)$ in 556 patients with recurrent platinum-resistant EOC also showed no superiority of CPI treatment [14]. The recruitment of the JAVELIN Ovarian PARP 100 study, which was meant to have assessed the activity of both avelumab and the PARP inhibitor talazoparib combined with chemotherapy in the primary treatment of EOC, was subsequently halted.

Other recent phase 1 and 2 monotherapy studies of three PD1/PD-L1 inhibitors (nivolumab, pembrolizumab, avelumab) reported modest ORRs ranging from 8.0 to $22.0 \%$ and a median PFS of 1.9 to 8.2 months, further questioning the efficacy of CPI monotherapy in EOC patients [9, 15, 16]. However, results of only few clinical trials combining CPIs with antiangiogenic agents and/or PARP inhibitors have been published to date $[11,12]$. Of note, the most important large trials are still ongoing.

\section{Activity of combination therapies including checkpoint inhibitors for EOC}

The concept of combining CPI with PARP inhibitors was investigated in the phase 2 TOPACIO/Keynote162 study. Sixty-two patients received niraparib (200 mg daily) and pembrolizumab (200 mg q3w) for recurrent EOC, reporting an ORR of $18.0 \%$ (90\% CI $11.0-29.0 \%)$ with a PFS of 3.4 months (95\% CI 2.1-5.1). However, no resilient biomarker for therapy response could be defined. BRCA, HRD, and PD-L1 expression 
Table 1 Current trials investigating response to checkpoint inhibitor therapy in patients with advanced recurrent epithelial ovarian cancer

\begin{tabular}{|c|c|c|c|c|c|c|c|}
\hline Author & Study name & Phase & Agent/target & Size & Patient cohort & ORR & PFS \\
\hline \multirow[t]{2}{*}{$\begin{array}{l}\text { Hamanishi et al. } \\
\text { (2015) [7] }\end{array}$} & (UMIN000005714) & 2 & $\begin{array}{l}\text { Nivolumab } \\
1 \text { or } 3 \mathrm{mg} / \mathrm{kg} \text { q2w } \\
\text { (PD-1) }\end{array}$ & $n=20$ & Platinum-resistant & $\begin{array}{l}15.0 \% \\
(95 \% \mathrm{Cl} \\
3.2-37.9)\end{array}$ & $\begin{array}{l}3.5 \text { months } \\
(95 \% \mathrm{Cl} 1.7-3.9)\end{array}$ \\
\hline & $\begin{array}{l}\text { Expansion Study } \\
\text { (NCT01375842) }\end{array}$ & 1a & $\begin{array}{l}\text { Atezolizumab } \\
0.3-15 \mathrm{mg} / \mathrm{kg} \text { qw3 } \\
\text { (PD-L1) }\end{array}$ & $n=12$ & - & $\begin{array}{l}22.0 \% \\
\text { (not reported) }\end{array}$ & $\begin{array}{l}2.9 \text { months } \\
(95 \% \text { Cl 1.3-5.5) }\end{array}$ \\
\hline $\begin{array}{l}\text { Varga et al. (2019) } \\
\text { [8] }\end{array}$ & $\begin{array}{l}\text { KEYNOTE } 028 \\
\text { (NCT02054806) }\end{array}$ & $1 b$ & $\begin{array}{l}\text { Pembrolizumab } \\
10 \mathrm{mg} / \mathrm{kg} \mathrm{q} 2 \mathrm{w} \\
(\mathrm{PD}-1)\end{array}$ & $n=26$ & $\begin{array}{l}\text { Progression under previ- } \\
\text { ous therapy, } \\
\text { PDL1 positive }\end{array}$ & $\begin{array}{l}11.5 \% \\
(2.4-30.2)\end{array}$ & $\begin{array}{l}1.9 \text { months } \\
(95 \% \text { Cl } 1.8-3.5)\end{array}$ \\
\hline $\begin{array}{l}\text { Matulonis et al. } \\
\text { (2019) [9] }\end{array}$ & $\begin{array}{l}\text { KEYNOTE-100 } \\
\text { (NCT02674061) }\end{array}$ & 2 & $\begin{array}{l}\text { Pembrolizumab } \\
200 \mathrm{mg} \mathrm{q} 3 \mathrm{w} \\
\text { (PD-1) }\end{array}$ & $n=376$ & $\begin{array}{l}\text { Platinum sensitive or } \\
\text { resistant }\end{array}$ & $\begin{array}{l}8.0 \% \\
(95 \% \mathrm{Cl} \\
5.4-11.2)\end{array}$ & $\begin{array}{l}2.1 \text { months } \\
(95 \% \mathrm{Cl} 2.1-2.6)\end{array}$ \\
\hline \multirow[t]{2}{*}{$\begin{array}{l}\text { Disis et al. (2019) } \\
\text { [10] }\end{array}$} & $\begin{array}{l}\text { JAVELIN Solid } \\
\text { Tumor } \\
\text { NCT01772004 }\end{array}$ & $1 b$ & $\begin{array}{l}\text { Avelumab } \\
10 \mathrm{mg} / \mathrm{kg} \mathrm{q} 2 \mathrm{w} \\
\text { (PD-L1) }\end{array}$ & $n=125$ & $\begin{array}{l}\text { Platinum sensitive or } \\
\text { resistant }\end{array}$ & $\begin{array}{l}9.6 \% \\
(95 \% \mathrm{Cl} \\
5.1-16.2)\end{array}$ & $\begin{array}{l}2.6 \text { months } \\
(95 \% \mathrm{Cl} 1.4-2.8)\end{array}$ \\
\hline & NCT01611558 & 2 & $\begin{array}{l}\text { Ipilimumab } 10 \mathrm{mg} / \mathrm{kg} \text { q3w } \\
\text { (CTLA-4) }\end{array}$ & $n=40$ & Platinum-sensitive & $\begin{array}{l}10.3 \% \\
(95 \% \mathrm{Cl} \\
2.9-34.2)\end{array}$ & Results pending \\
\hline $\begin{array}{l}\text { Konstantinopoulos } \\
\text { et al. (2019) [11] }\end{array}$ & $\begin{array}{l}\text { TOPACI0/ } \\
\text { Keynote-162 } \\
\text { NCT02657889 }\end{array}$ & $1 / 2$ & $\begin{array}{l}\text { Niraparib } \\
200 \mathrm{mg} \\
\text { daily + pembrolizumab } \\
200 \mathrm{mg} \text { q3w } \\
\text { (PD-1) }\end{array}$ & $n=62$ & Platinum-resistant & $\begin{array}{l}18.0 \% \\
(90 \% \mathrm{Cl} \\
11.0-29.0)\end{array}$ & $\begin{array}{l}3.4 \text { months } \\
(95 \% \mathrm{Cl} 2.1-5.1)\end{array}$ \\
\hline $\begin{array}{l}\text { Drew et al. (2019) } \\
\text { [12] (Abstract) }\end{array}$ & $\begin{array}{l}\text { MEDIOLA } \\
\text { NCT02734004 }\end{array}$ & 2 & $\begin{array}{l}\text { Olaparib } \\
300 \mathrm{mg} \mathrm{BID}+\text { durvalumab } \\
1500 \mathrm{mg} \mathrm{q} 4 \mathrm{w} \\
\text { (PD-L1) }\end{array}$ & $n=32$ & BRCA mutated & $\begin{array}{l}71.9 \% \\
(95 \% \mathrm{Cl} \\
53.3-86.3)\end{array}$ & $\begin{array}{l}11.1 \text { months } \\
(95 \% \mathrm{Cl} \\
8.2-15.9)\end{array}$ \\
\hline
\end{tabular}

were not ascertained as reliable predictive biomarkers [11].

Preliminary results of the phase 2 basket trial MEDIOLA assessing activity of olaparib (300 mg BID) and durvalumab (1500 mg q4w) in 32 recurrent BRCAmutated, platinum-sensitive EOC patients report a highly promising ORR of $71.9 \%$ (95\% CI 53.3-86.3\%) with a median PFS of 11.1 months (95\% CI 8.2-15.9) [12]. As the PARP inhibitor is particularly active in the cohort of BRCA-mutated patients, it is difficult to estimate the additional benefit of durvalumab for patients in this trial.

Another phase 2/3 trial, the NRGGY009 (NCT0283 9707), was suspended after an interim analysis, having investigated atezolizumab and/or bevacizumab in combination with PLD in a recurrent platinum-resistant setting. Final results have not been published to date. A triple therapy of durvalumab (1120 mg q3w), olaparib (300 mg BD) and bevacizumab (15 mg/kg) is currently being assessed in the DUO-O phase 3 study (NCT03737643) in first-line therapy of advanced EOC [17], whereas the phase 2 OPAL study (NCT03574779) is investigating the activity of the PD-1 inhibitor TSR-042 (500 mg q3w) combined with niraparib (200/300 mg daily) and bevacizumab (15 mg/kg) in a recurrent setting.

Important ongoing phase 3 studies include the IMaGYN050 (NCT03038100) and the ATHENA trial (NCT03522246), which are assessing the response to atezolizumab/bevacizumab and nivolumab/rucaparib combined with platinum-based chemotherapy in first-line treatment, respectively. These trials will further elucidate the value of combining CPIs with PARP inhibitors and/or antiangiogenic drugs, such as bevacizumab or cediranib.

\section{Safety signals and therapy-related toxicity}

The treatment with PD1/PD-L1 and CTLA-4 inhibitors brought a new profile of toxic effects to the field of gynecologic oncology. Typical CPI-associated side effects arise from $\mathrm{T}$ cell over-activation, leading to $\mathrm{T}$ cell infiltration of various organ systems and thereby autoimmune-like symptoms or "immunerelated adverse events" (irAEs). Typically, the majority of these side effects are mild to moderate. According to a recent meta-review, most frequent irAEs comprise diarrhea $(9.5 \%, 95 \%$ CI 8.4-10.6), hypothyroidism $(6.1 \%$, 95\%CI 5.4-6.9), AST increase (3.4\%, 95\%CI 2.9-3.9), vitiligo (3.3\%, 95\%CI 2.8-3.8), ALAT increase $(3.1 \%$, 95\%CI 2.7-3.6), hyperthyroidism (2.8\%, 95\% CI $2.4-3.3)$ and pneumonitis $(2.8 \%, 95 \% \mathrm{CI}$ 2.4-3.2). Some patients, however, may experience grade 3 or higher irAEs, including AST increase $(0.8 \%$, 95\%CI 0.6-1.0), ALT increase $(0.7 \%, 95 \%$ CI $0.5-0.9)$, pneumonitis $(0.7 \%, 95 \%$ CI $0.5-0.9)$ with a very small share $(0.45 \%)$ dying of treatment-related sequelae. Among those patients, pneumonitis was the most 
frequently reported cause of death [18]. Of note, blocking of CTLA-4 was associated with higher AE rates than PD1/PD-L1 inhibition due to a more global and less targeted activation of T cells [19].

Detailed organ-specific guidelines for the management of CPI-treatment-related toxicities have been published by the ASCO. Following these recommendations, CPI therapy may be continued under close monitoring for grade 1 toxicities, whereas therapy should be temporarily paused for grade 2 toxicities. CPI therapy may be continued after remission of grade 2 symptoms with the possibility of administering corticosteroid. Starting with grade 3 toxicities, therapy is to be halted and corticosteroids should be applied over a course of at least 4-6 weeks (prednisone or methylprednisolone $1-2 \mathrm{mg} / \mathrm{kg} /$ day, respectively). Therapy should be permanently terminated in case of grade 4 toxicities with the exception of endocrine dysfunctions controllable by hormone replacement [20].

\section{Biomarkers for checkpoint inhibitor response in EOC}

To date, the combined positive score (CPS), a quantifier of PD-L1 expression, appears to be the most precise predictive biomarker for CPI response. As evaluated by Matulonis et al. in 2019, ORRs for CPI treatment in EOC patients increase from $5.0 \%$ at a CPS $<1$ up to $17 \%$ at a CPS $>10$. The most important limitation of the CPS is its lack of a homogenous validation and staining results interpretation due to missing standardization and use of different staining antibodies. Potential future biomarkers for CPI response in EOC may include both BRCA and microsatellite status: BRCA-mutated EOCs were associated with a higher TMB, more tumor-infiltrating leukocytes and higher PDL-1 expression. Moreover, as suggested by Wieser et al. in 2018, PD-L1 expression may be controlled by interferon-gamma, which in return is affected by both TP53 and BRCA mutation status. These findings, however, are to be considered highly experimental and clinical studies will be necessary to confirm these preliminary results $[9,21-23]$.

\section{Take home message}

Early clinical trials investigating monotherapy for EOC reported CPIs to be a safe treatment without additional safety flags. Efficacy results for CPI monotherapy, however, remain controversial as response rates seem to be rather modest. Ongoing phase 3 trials combining CPI with antiangiogenic agents and/or PARP inhibitors will further elucidate possible synergistic effects to enhance $\mathrm{CPI}$ therapeutic efficacy in EOC patients. Modestly responsive solid tumors such as EOC particularly emphasize the urge to define resilient predictive biomarkers as this would improve the selection of patient subsets who will likely benefit from CPI treatment in the future.
Funding Open access funding provided by Medical University of Vienna.

Conflict of interest S. Polterauer received compensation for lecturing activities, advisory boards or scientific grants from Astra Zeneca, Celgene, MSD, PharmaMar, Roche, Roche Diagnostics, Meda Pharma, Tesaro, and Vifor Pharma. The disclosed funding is not related to the research reported. C. Grimm received consultant fees from AstraZeneca, Celgene, MSD, PharmaMar, Roche, GSK/Tesaro, Vifor Pharma and Clovis, compensation for lecturing activities from Amgen, AstraZeneca, MSD, PharmaMar, Roche, GSK/Tesaro and direct research funding: Meda Pharma, Roche Diagnostics. The disclosed funding is not related to the research reported. T. Bartl and V. Paspalj declare that they have no competing interests.

Open Access This article is licensed under a Creative Commons Attribution 4.0 International License, which permits use, sharing, adaptation, distribution and reproduction in any medium or format, as long as you give appropriate credit to the original author(s) and the source, provide a link to the Creative Commons licence, and indicate if changes were made. The images or other third party material in this article are included in the article's Creative Commons licence, unless indicated otherwise in a credit line to the material. If material is not included in the article's Creative Commons licence and your intended use is not permitted by statutory regulation or exceeds the permitted use, you will need to obtain permission directly from the copyright holder. To view a copy of this licence, visit http://creativecommons.org/licenses/by/4.0/.

\section{References}

1. Haanen JB, Robert C. Immune checkpoint inhibitors. Prog Tumor Res. 2015;42:55-66.

2. Steuer CE, Ramalingam SS. Tumor mutation burden: leading immunotherapy to the era of precision medicine? J Clin Oncol. 2018;36(7):631-2.

3. Cristescu R, Mogg R, Ayers M, Albright A, Murphy E, Yearley J, et al. Pan-tumor genomic biomarkers for PD-1 checkpoint blockade-based immunotherapy. Science. 2018;362 (6411):eaar3593. https://doi.org/10.1126/ science.aar3593.

4. Li A, Yi M, Qin S, Chu Q, Luo S, Wu K. Prospects for combining immune checkpoint blockade with PARP inhibition. JHematolOncol. 2019;12(1):98.

5. Yi M, Jiao D, Qin S, Chu Q, Wu K, Li A. Synergistic effect of immune checkpoint blockade and anti-angiogenesis in cancer treatment. Mol Cancer. 2019;18(1):60.

6. Voron T, Colussi O, Marcheteau E, Pernot S, Nizard M, PointetAL, etal. VEGF-Amodulates expression ofinhibitory checkpoints on CD8+ T cells in tumors. J Exp Med. 2015;212(2):139-48.

7. Hamanishi J, Mandai M, Ikeda T et al. Safety and Antitumor Activity of Anti-PD-1 Antibody, Nivolumab, in Patients With Platinum-Resistant Ovarian Cancer. J Clin Oncol. 2015;33(34):4015-4022. https://doi.org/10.1200/ JCO.2015.62.3397.

8. Varga A, Piha-Paul S, Ott PA, Mehnert JM, Berton-Rigaud D, Morosky A, Yang P, Ruman J, Matei D. Pembrolizumab in patients with programmed death ligand 1-positive advanced ovarian cancer: Analysis of KEYNOTE-028. Gynecol Oncol. 2019;152(2):243-250. https://doi.org/10.1016/j. ygyno.2018.11.017.

9. Matulonis UA, Shapira-Frommer R, Santin AD, Lisyanskaya AS, Pignata S, Vergote I, et al. Antitumor activity and 
safety of pembrolizumab in patients with advanced recurrent ovarian cancer: results from the phase II KEYNOTE-100 study. Ann Oncol. 2019;30(7):1080-7.

10. Disis ML, Taylor MH, Kelly K, Beck JT, Gordon M, Moore KM, Patel MR, Chaves J, Park H, Mita AC, Hamilton EP, Annunziata CM, Grote HJ, von HeydebreckA, Grewal J, Chand V, Gulley JL. Efficacy and safety of avelumab for patients with recurrent or refractory ovarian cancer: phase $1 \mathrm{~b}$ results from the JAVELIN solid tumor trial. JAMA Oncol. 2019;5(3):393-401. https://doi.org/10.1001/jamaoncol. 2018.6258

11. Konstantinopoulos PA, Waggoner S, Vidal GA, Mita M, Moroney JW, Holloway R, et al. Single-arm phases 1 and 2 trial of niraparib in combination with pembrolizumab in patients with recurrent platinum-resistant ovarian carcinoma. JAMAOncol. 2019;5(8):1141-9.

12. Drew Y, Kaufman B, Banerjee S, Lortholary A, Hong SH, Park YH, et al. 1190PDphase II study of olaparib + durvalumab (MEDIOLA): updated results in germline BRCAmutated platinum-sensitive relapsed (PSR) ovarian cancer (OC). Ann Oncol. 2019; https://doi.org/10.1093/annonc/ mdz253.016.

13. Pfizer MKa. Provide update on JAVELIN ovarian 100 trial of avelumab in previously untreated advanced ovarian cancer. 2018. www.emdgroup.com/en/news/javelinovarian-100-21-12-2018.html. Accessed 28 Oct 2019.

14. Pfizer MKa. Provide update on avelumab in platinumresistant/refractory ovarian cancer. 2018. www.emdgroup. com/en/news/avelumab-1x-11-2018.html. Accessed 28 Oct 2019 .

15. Infante JR, Braiteh F, Emens LA, Balmanoukian AS, Oaknin A, Wang Y, et al. Safety, clinical activity and biomarkers of atezolizumab (atezo) in advanced ovarian cancer (OC). Ann Oncol. 2016; https://doi.org/10.1093/ annonc/mdw374.18.

16. VargaA, Piha-PaulSA, OttPA, MehnertJM, Berton-RigaudD, Johnson EA, et al. Antitumor activity and safety of pembrolizumab in patients (pts) with PD-L1 positive advanced ovarian cancer: interim results from a phase Ib study. JClin Oncol. 2015;33(15):5510.

17. Harter P, Bidziński M, Colombo N, Floquet A, Pérez MJR, Kim J-W, et al. DUO-O: a randomized phase III trial of durvalumab (durva) in combination with chemotherapy and bevacizumab (bev), followed by maintenance durva, bev and olaparib (olap), in newly diagnosed advanced ovarian cancer patients. JClin Oncol. 2019;37(15):TPS5598TPS.

18. Wang Y, Zhou S, Yang F, Qi X, Wang X, Guan X, et al. Treatment-related adverse events of PD-1 and PD-L1 inhibitors in clinical trials: a systematic review and meta-analysis. JAMAOncol. 2019;5(7):1008-19.

19. Day D, Hansen AR. Immune-related adverse events associated with immune checkpoint inhibitors. BioDrugs. 2016;30(6):571-84.

20. BrahmerJR, Lacchetti C, Schneider BJ, Atkins MB, Brassil KJ, Caterino JM, etal. Management of immune-related adverse events in patients treated with immune checkpoint inhibitor therapy: American society of clinical oncology clinical practice guideline. J Clin Oncol. 2018;36(17):1714-68.

21. Wieser V, Gaugg I, Fleischer M, Shivalingaiah G, Wenzel S, Sprung S, et al. BRCA1/2 and TP53 mutation status associates with PD-1 and PD-L1 expression in ovarian cancer. Oncotarget. 2018;9(25):17501-11.

22. Bellone S, Buza N, Choi J, Zammataro L, Gay L, Elvin J, et al. Exceptional response to pembrolizumab in a metastatic, chemotherapy/radiation-resistant ovarian cancer patient harboring a PD-L1-genetic rearrangement. Clin Cancer Res. 2018;24(14):3282-91.

23. Zhao P, Li L, Jiang X, Li Q. Mismatch repair deficiency/ microsatellite instability-high as a predictor for anti-PD1/PD-L1 immunotherapy efficacy. J Hematol Oncol. 2019;12(1):54.

Publisher's Note Springer Nature remains neutral with regard to jurisdictional claims in published maps and institutional affiliations.

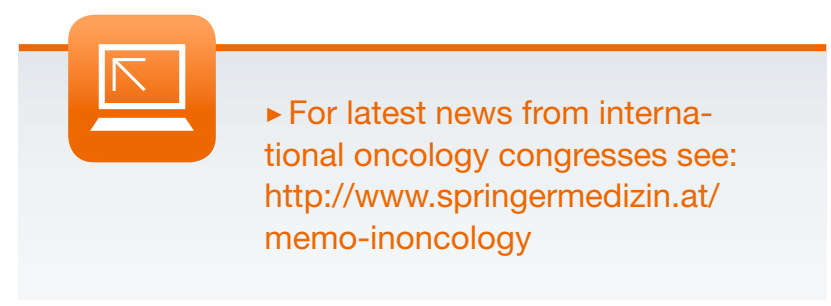

